\title{
Capturing Problem
}

National Cancer Institute

\section{Source}

National Cancer Institute. Capturing Problem. NCI Thesaurus. Code C63027.

Problem associated with the inability of the device to achieve successful depolarization and contraction of a cardiac chamber caused by a pacemaker output pulse. 